\title{
Anticorpos monoclonais para o tratamento de enxaqueca (migrânea)
}

\author{
Monoclonal antibodies for the treatment of migraine \\ (migraneous)
}

\section{Anticuerpos monoclonales para el tratamiento de la migraña (migráneo)}

\author{
Flavianny Braga Barbosa de Oliveira ${ }^{1}$, Francisco Diogo Almeida Silva ${ }^{1}$, \\ George Icaro Maia Farias ${ }^{1}$, Ialy Beatriz Lima Ferreira ${ }^{1}$, Jéssika \\ Jannyne Gomes de Lima1, Maria Emília Matos Pequeno Dias ${ }^{1}$, \\ Francisco José Batista de Lima Júnior ${ }^{2}$
}

1.Discente do curso de Medicina, Centro Universitário UniFacisa, Campina Grande-PB, Brasil. 2.Farmacêutico, Doutor em Farmacologia, Professor do Centro Universitário UniFacisa, Campina Grande-PB, Brasil.

\begin{abstract}
Resumo
Introdução. A Migrânea é uma condição sindrômica caracterizada por cefaleias que ocasionalmente incapacitam seus portadores. Atualmente é uma condição onerosa para os sistemas de saúde e que o tratamento convencional não consegue ter eficácia em grande parte dos doentes. Assim, terapias relacionadas aos neuropeptídeos envolvidos com a fisiopatologia da doença têm se mostrado alvos promissores. Método. Foram utilizados os bancos de dados do Scielo e Pubmed, utilizando-se das combinações de descritores: "migraine" e "monoclonal antibodies". Resultados. Diante da ineficácia de medicamentos tradicionalmente usados e de seus efeitos colaterais, os anticorpos monoclonais ganharam aceitação mundial pela capacidade de direcionar seletivamente as células indutoras da migrânea. Devido a essa seletividade, proporcionam a alta segurança, o baixo risco de interação medicamentosa e nenhum efeito imunomodulador, mostrando-se como grande alternativa para o tratamento preventivo para a enxaqueca e com redução significativa dos sintomas post-drome. Todavia, a ausência de resposta ou recaída em alguns pacientes, apontam para uma compreensão insatisfatória dos perfis farmacocinético e da farmacodinâmica, o que leva a uma eficácia limitada ou diminuída. Conclusão. A comercialização desses medicamentos indica resultados promissores no tratamento e na prevenção de episódios de enxaqueca. Entretanto, o principal entrave dessa alternativa terapêutica está nos elevados custos para sua comercialização em comparação às terapêuticas tradicionais.
\end{abstract}

Unitermos. Imunoterapia;Peptídeo Relacionado com Gene de Calcitonina; Agonistas do Receptor de Serotonina

\begin{abstract}
Introduction. Migraine is a syndromic condition characterized by headache's crisis that occasionally disables people who have this illness. Currently, it is an onerous condition for health systems and conventional treatment is not totally effective in significant part of patients. Thus, therapies related to neuropeptides involved in the pathophysiology of the disease have been promising targets. Method. We used the Scielo and Pubmed databases, using combinations of descriptors: "migraine" and "monoclonal antibodies". Results. In view of the ineffectiveness of traditional medicines used and their effects, monoclonal antibodies gain worldwide participation due to the ability to selectively target migraine-inducing cells. Calculate this selectivity, provide high safety, or low risk of drug interaction and no immunomodulatory effect, showing itself as a great alternative for the preventive treatment of migraine and with significant reduction of post-drome symptoms. However, the lack of response or relapse in some patients, points to an unsatisfactory understanding of pharmacokinetic and
\end{abstract}


pharmacodynamic records, or that leads to a limited reduction. Conclusion. The commercialization of these drugs indicates promising results in the treatment and detection of migraine. However, the main thing that enters this therapeutic alternative is the high costs for its commercialization in comparison to traditional therapies.

Keywords. Immunotherapy;Calcitonin Gene-Related Peptide; Serotonin Receptor Agonists

\title{
Resumen
}

Introducción. La migraña es una condición sindrómica caracterizada por la cefalea que ocasionalmente desactiva a sus portadores. Actualmente es una condición costosa para los sistemas de salud y el tratamiento convencional no es efectivo en la mayoría de los pacientes. Por lo tanto, las terapias relacionadas con los neuropéptidos involucrados en la fisiopatología de la enfermedad han demostrado ser objetivos prometedores. Método. Se utilizaron las bases de datos Scielo y Pubmed, utilizando las combinaciones de descriptores: "migraine" y "monoclonal antibodies". Resultados. En vista de la ineficacia de los medicamentos utilizados tradicionalmente y sus efectos secundarios, los anticuerpos monoclonales han ganado aceptación mundial por lacapacidad de atacar selectivamente las células inductoras de migraña. Debido a esta selectividad, proporcionan una alta seguridad, un bajo riesgo de interacción farmacológica y ningún efecto inmunomodulador, mostrándose como una gran alternativa para el tratamiento preventivo de la migraña y con una reducción significativa de los síntomas posteriores al drome. Sin embargo, la falta de respuesta o recaída enalgunos pacientes, apuntan a una comprensión insatisfactoria de los perfiles farmacocinéticos y farmacodinámicos, lo que conduce a una eficacia limitada o diminuta. Conclusión. La comercialización de estos medicamentos indica resultados prometedores en el tratamiento y prevención de episodios de migraña. Sin embargo, el principal obstáculo para esta alternativa terapéutica son los altos costos para su comercialización en comparación con las terapias tradicionales.

Palabras clave. Inmunoterapia; Péptido Relacionado con Gen de Calcitonina; Agonistas de Receptores de Serotonina

Trabalho realizado no Centro Universitário UniFacisa, Campina Grande-PB, Brasil.

\section{INTRODUÇÃO}

\author{
A migrânea (enxaqueca) é uma das principais causas
} de incapacidade em todo o mundo, particularmente nos indivíduos com menos de 50 anos $^{1}$. Trata-se de uma condição debilitante, frequentemente tratada no cuidado primário, que gera altos custos para os sistemas de saúde e perda do tempo produtivo dos pacientes. Apesar da fisiopatologia da migrânea não estar totalmente elucidada, a ativação do sistema trigeminovascular parece desempenhar 
papel fundamental. Ramos do nervo trigêmeo podem inervar a face e parte das meninges, incluindo vasos intracraniais. A liberação de neuropeptídeos, como o peptídeo relacionado ao gene da calcitonina (CGRP), por esses ramos perivasculares do nervo trigêmeo causam vasodilatação, que resulta na ativação de nociceptores e percepção dolorosa².

Essa comorbidade não se caracteriza apenas por uma cefaleia específica, mas uma síndrome com várias fases. Dessa forma, cada fase possui uma distinta patogênese e influencia do tratamento empregado ${ }^{3}$. Os pacientes com essa doença descrevem sentir mais de um tipo de cefaleia, com cada condição apresentando características clínicas consideravelmente diferentes ${ }^{1}$.

Por conseguinte, a migrânea pode ser subdividida em dois tipos: enxaqueca episódica e enxaqueca crônica. Segundo os critérios da $3^{\circ}$ classificação internacional de cefaleias, para o diagnóstico de enxaqueca crônica é necessário que o paciente apresente 15 dias de cefaleias mensais e características associadas à enxaqueca são necessárias apenas em 8 desses 15 dias, podendo existir uso excessivo de medicação concomitante com diagnóstico. Além disso, as crises esporádicas são descritas como ataques pontuais ${ }^{4}$.

Em geral, os ataques de enxaqueca podem ser divididos em 4 fases de acordo com a ocorrência da cefaleia, os eventos que a antecedem e a sucedem, sendo elas: fase prodrômica, a aura, cefaleia e a fase de recuperação. 
A fase prodrômica (também conhecida como fase premonitória) tem possibilidade de ocorrer algumas horas ou dias antes do evento da cefaleia em si, podendo ser caracterizada por uma variedade de sintomas não relacionados à cefaleia, tais como: poliúria, fotofobia, cervicalgia, dificuldades de concentração, entre outros ${ }^{1}$. Também pode ser observada através de tomografias avançadas de emissão de pósitron e ressonâncias magnéticas funcionais ${ }^{3}$. Alguns estudos eletrofisiológicos mostraram mudanças na função cerebral nesta fase, particularmente nos circuitos que conectam o tálamo e o córtex. Essas modificações na atividade talâmica e tálamocortical são respaldadas em estudos que apontaram o tálamo como mediador de alodinia cutânea e exacerbação da cefaleia desencadeada por exposição luminosa, características centrais de um ataque de enxaqueca e poderiam representar um alvo terapêutico considerável para abordagens farmacológicas e neuromoduladoras ${ }^{1}$.

Cerca de um terço dos ataques de enxaqueca são precedidos pela fase conhecida como aura, causada por um evento dinâmico de depressão que se espalha pelo córtex com diminuição das despolarizações neuronais. Quando presente, essa fase pode durar até 60 minutos $^{2,5,3}$. Assim, essa fase se manifesta por um escotoma cintilante clássico em $50 \%$ dos casos e luzes intermitentes ou escotoma sem cintilação no restante dos casos. Embora os sintomas visuais sejam prevalentes, os sintomas sensoriais, de linguagem e olfativos também são comuns e podem ocorrer em conjunto 
ou independentemente dos sintomas visuais. As características clínicas da aura visual correspondem a hiperativação de áreas específicas do córtex ${ }^{2,5}$.

A fase de cefaleia, dura em torno de $4 \mathrm{~h}$ a $72 \mathrm{~h}$, é de forte intensidade, latejante/pulsátil, piorando com as atividades do dia-a-dia, a dor tem característica unilateral em dois terços das crises, geralmente mudando de lado da face. É uma desordem que envolve a ativação do sistema trigeminovascular que libera diversos neurotransmissores ${ }^{5}$.

A fase de recuperação (em inglês, postdrome), é o estágio que sucede os ataques de cefaleia, e incluem sintomas que não são diretamente relacionados à mesma, dentre os quais, incluem fadiga, desordens do TGI e malestar $^{3}$, é considerada uma fase de "exaustão", na qual, alguns pacientes necessitam de um período de descanso para seu completo restabelecimento ${ }^{5}$.

Atualmente, o tratamento convencional para enxaqueca é realizado com triptanos. O efeito terapêutico dessas drogas se dá devido à sua ação agonista sobre os receptores de serotonina 5HT1B e 5HT1D, o que causa a vasoconstrição craniana e a inibição da informação neurogênica que ocorre nessa comorbidade. Porém, vale-se ressaltar que embora sejam drogas seguras, os efeitos colaterais relacionados à classe (por exemplo, aperto no peito e desconforto na garganta, dor muscular e parestesia) são relatados por até $24 \%$ dos pacientes que usam triptanos orais e por $40 \%$ dos pacientes que usam a formulação subcutânea. Além disso, outro ponto de relevância é a eficácia relativamente baixa, 
pois $35 \%$ dos participantes em ensaios clínicos randomizados (RCTs) não se beneficiam da administração de triptanos ${ }^{6}$.

O surgimento de alternativas de tratamentos é crucial para o tratamento de casos refratários. Um alvo farmacológico potencial é CGRP, mediador que tem níveis elevados durante a crise de enxaqueca e declina depois de encerrada a crise ou com uso de medicamentos específicos para alívio, como os triptanos. Terapias que antagonizem especificamente o CGRP ou sua ligação aos receptores são promissoras e, nesse sentido, os anticorpos monoclonais destacam-se pela sua especificidade e melhora do quadro clínico sem efeito vasoconstrictor ${ }^{5,7}$.

O presente trabalho teve como objetivo estudar a literatura relacionada ao uso de anticorpos monoclonais no tratamento da migrânea, estabelecendo um comparativo com as terapias já empregadas para essa condição.

\section{MÉTODO}

Realizamos uma revisão descritiva da literatura realizada no período de fevereiro a abril de 2020, utilizando artigos retirados do banco de dados Scielo e Pubmed. Para a seleção dos artigos do estudo foram utilizadas as seguintes combinações de descritores: "migraine" e "monoclonal antibodies".

A pesquisa sucedeu-se em duas etapas. A primeira etapa da revisão consistiu em análise dos resumos, que 
foram identificados, avaliados e selecionados independentemente com base no potencial de relevância para redação do texto e aprofundamento sobre o assunto. A segunda etapa constituiu da extração de dados dos estudos selecionados. Todos os registros elegíveis foram lidos integralmente e dados disponíveis no texto foram extraídos considerando autor, desenho do estudo e ano de publicação, dando preferência àqueles publicados nos últimos 7 anos.

\section{RESULTADOS e DISCUSSÃO}

Foram encontrados 324 artigos com base nos descritores empregados para a pesquisa, dos quais foram selecionados 21 artigos, de acordo com os critérios de inclusão e exclusão dos autores. Os bancos de dados utilizados foram Pubmed e Scielo, com trabalhos publicados no período entre 2013 a 2020. Para elaboração do presente estudo, foram empregados 20 artigos na língua inglesa e 01 na língua portuguesa.

\section{Terapias consolidadas para o tratamento da enxaqueca}

\section{Triptanos}

A terapia para migrânea inclui medidas farmacológicas e não farmacológicas. Com isso, todos os casos devem ser tratados, independentemente da intensidade acometida. Atualmente, a primeira linha de escolha para pacientes que apresentam ataques de enxaqueca moderados a graves é 
através do uso de agonistas do subtipo $5-\mathrm{HT} 1_{B} / 1_{D}$ do receptor da serotonina, denominados triptanos (Tabela 1 ). 0 mecanismo de ação dessa classe de medicamentos é baseado na vasoconstrição e na inibição da liberação de mediadores inflamatórios neurogênicos, como o CGRP33.

Existem quatro medicamentos dessa classe que são comercializados no Brasil: sumatriptano, naratriptano, zolmitriptano e rizatriptano. O sumatriptano, um medicamento pioneiro, possui muitas formas de administração: comprimidos (25mg, 50mg e 100mg), injeção subcutânea de $6 \mathrm{mg}$ e spray nasal de $10 \mathrm{mg} /$ dose. 0 uso subcutâneo é o de maior eficiência e rapidez de ação, porém, o efeito adverso mais comum a esse uso é a sonolência, embora possa ocorrer com qualquer fármaco da classe. Além disso, alguns pacientes relatam sentir aperto no peito, na região nucal ou cranial alguns minutos após o uso dessas substâncias. Já o naratriptano, vendido em comprimidos de 2,5mg, apresenta a desvantagem de ser menos potente e ter um início de ação mais lento, quando comparado ao sumatriptano ${ }^{8}$.

Supõe-se que cerca de $30 \%$ dos pacientes não respondem satisfatoriamente ao uso de algum fármaco da classe dos triptanos ${ }^{8}$. Ademais, vale ressaltar que este grupo de medicamentos é contraindicado para pacientes com doenças cardiovasculares e cerebrovasculares prévias, além daqueles com hipertensão não controlada, devido ao seu mecanismo de ação ${ }^{3}$. 


\section{Derivados do ergot}

Os derivados do ergot (Tabela 1) são recomendados para uso como terapia de segunda ou terceira linha em pacientes selecionados ou com enxaqueca refratária9. Esses fármacos atuam tanto nos receptores serotonina $5 \mathrm{HT}-1_{\mathrm{B}} \mathrm{e}$ $5 \mathrm{HT}-1_{\mathrm{D}}$ quanto nos receptores colinérgicos muscarínicos e adrenérgicos, o que faz com que haja uma maior variedade de efeitos adversos ${ }^{8}$.

Com isso, por atuar nos mesmos receptores dos triptanos, os derivados do ergot são contraindicados em uso concomitante com esses medicamentos. Exemplo disso é a di-hidroergotamina, que só pode ser utilizada seis horas depois do uso dos triptanos. Por outro lado, após a ingestão inicial de di-hidroergotamina, o triptano só pode ser utilizado após 24 horas, devido à meia-vida mais longa desse medicamento ${ }^{8}$.

Um exemplo de derivado do ergot é a ergotamina, que nos seres humanos causa vasoconstrição nas artérias pulmonares, cerebrais e coronárias. Dentre seus efeitos colaterais, estão inclusos: náusea e/ou vômito, fraqueza nas pernas, dormência e formigamento nas extremidades. Seu uso é contraindicado em mulheres em idade fértil, pois o medicamento pode ocasionar alterações congênitas, principalmente em mulheres com doença vascular periférica, doença cardíaca coronária, hipertensão não controlada, acidente vascular cerebral e função renal ou hepática comprometida. Além disso, a ergotamina deve ser evitada 
em pacientes com enxaqueca hemiplégica, enxaqueca com aura do tronco cerebral e enxaqueca com aura prolongada ${ }^{10}$. No Brasil, o único derivado de ergot em uso é a dihidroergotamina, a qual está disponível apenas na forma de combinações fixas limitadas (associações com dipirona ou paracetamol, cafeína ou metoclopramida). Esse fármaco tem uma absorção por via oral irregular, não sendo possível afirmar qual concentração sérica será alcançada em sua administração. Além disso, também apresenta a desvantagem de aumentar sintomas como náuseas e vômitos em alguns pacientes e o seu uso durante 10 ou mais dias por mês conferirem um risco aumentado para o desenvolvimento de dor de cabeça do uso excessivo de medicamentos $(\mathrm{MOH}$, em inglês, migraine overuse headache $)^{10}$.

\section{Lasmiditan}

A busca por novos fármacos sem efeitos vasoconstritores levou ao desenvolvimento de uma alternativa terapêutica utilizando o Lasmiditan, um agente anti-enxaqueca de ação neural (NAAMA). Esse fármaco é considerado um agonista altamente seletivo do receptor 5$\mathrm{HT} 1_{\mathrm{F}}$ com interações reduzidas com outros subtipos de receptores de serotonina ${ }^{3}$. 
Tabela 1.Medicamentos usados atualmente no tratamento da enxaqueca8 ${ }^{8}$.

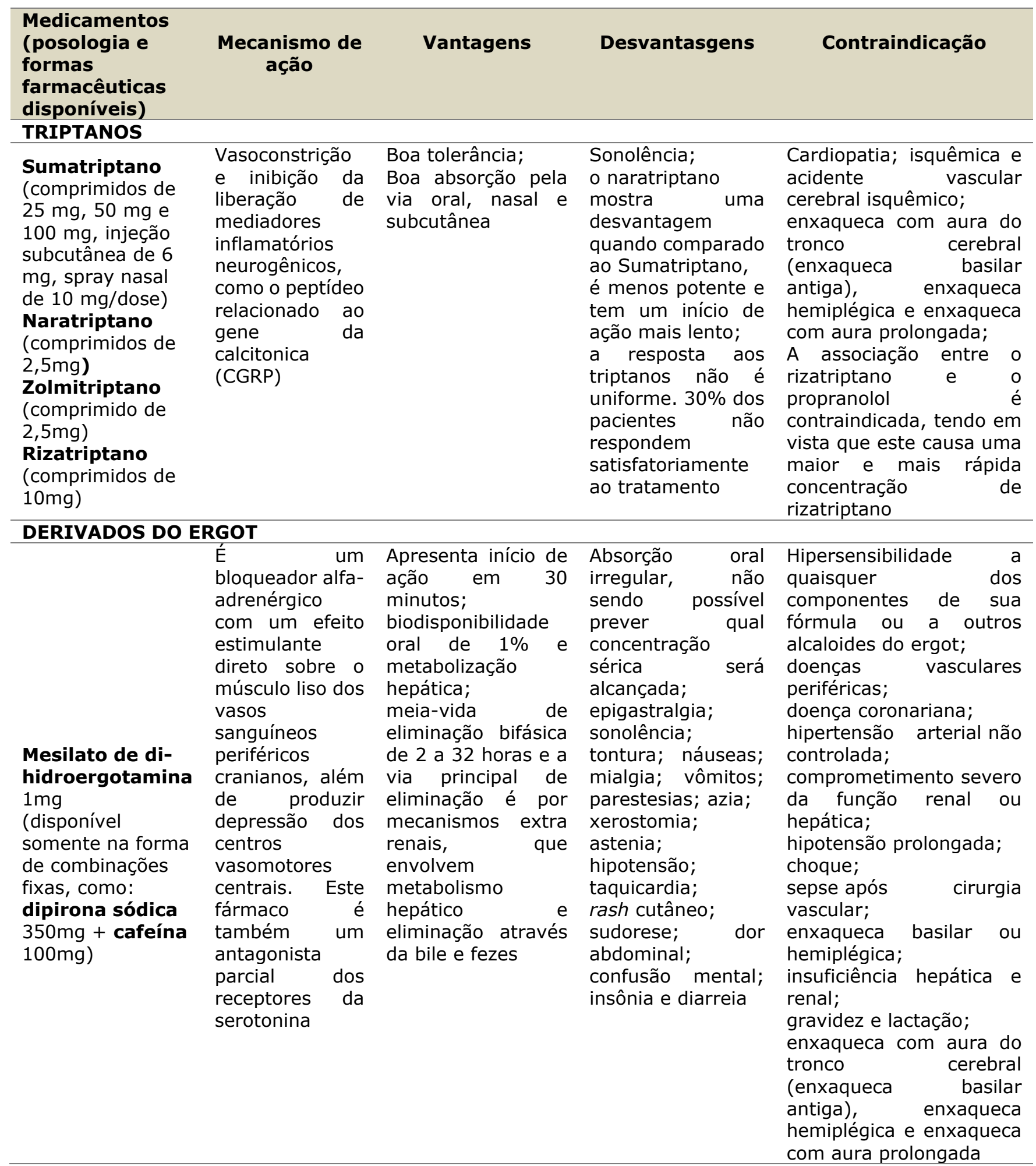


A partir disso, por estimulação dos receptores $5-\mathrm{HT} 1_{F}$ (que não podem ser encontrados nas células endoteliais ou musculares lisas dos vasos cerebrais) pode inibir as atividades neuronais centrais e periféricas e a liberação do neuropeptídeo CGRP, terminando assim a enxaqueca aguda. Esse fármaco é capaz de atravessar a barreira hematoencefálica e possui uma estrutura química que evita os efeitos colaterais comuns aos triptanos. Sintomas cardíacos, por exemplo, não foram observados, garantindo, assim, a segurança cardíaca, com ausência de arritmias ou quaisquer efeitos pós-arrítmicos ${ }^{3}$.

Contudo, existe a possibilidade de que o uso excessivo de Lasmiditan leve ao $\mathrm{MOH}$, que corresponde a enxaqueca causada pelo uso excessivo de medicações. Ademais, assim como os triptanos, também é uma molécula altamente lipofílica, o que pode limitar seu uso durante a gravidez e amamentação ${ }^{3}$.

\section{Gepants}

Outra alternativa farmacológica consolidada é a utilização dos antagonistas do receptor CGRP (gepants), os quais possuem uma alta afinidade pelos receptores CGRP de humanos e primatas não humanos em relação a outras espécies. Isso se deve a um resíduo específico localizado na interface entre as proteínas RAMP1 e CLR, indicando esta região como o local de ligação do antagonista ${ }^{11}$. Esses medicamentos, assim como os triptanos, atravessam a barreira hematoencefálica, fator esse que não está presente 
nos anticorpos monoclonais, os quais funcionam bem fora do sistema nervoso central (em particular, meninges) e não atravessaram a barreira hematoencefálica ${ }^{12}$.

O primeiro gepant a ser desenvolvido foi o olcegepant, que se mostrou muito potente e específico, no entanto funciona apenas quando administrado por via parenteral. Outros gepants comercializados apresentaram alta potência e boa biodisponibilidade oral, como por exemplo o telcagepant, porém, foram descontinuados devido a problemas com enzimas hepáticas ${ }^{11}$. Dessa forma, mostravam-se como alternativas promissoras aos triptanos, contudo, seu desenvolvimento foi interrompido por serem menos toleráveis devido à sua tendência a causar complicações hepáticas e cardiovasculares, ainda que demonstrassem eficácia comprovada contra a enxaqueca ${ }^{12}$.

\section{Anticorpos monoclonais: eficácia, especificidade e riscos}

Os anticorpos monoclonais (MAbs) e terapias derivadas de anticorpos estão amadurecendo na clínica, com mais de 70 produtos baseados em anticorpos atualmente comercializados e autorizados pela Food and Drug Administration (FDA) e European Medicines Agency (EMA), no valor de bilhões de dólares em todo o mundo e contribuição para mais de $53 \%$ dos biofármacos aprovados nos últimos 5 anos $^{13}$.

As drogas imunoterapêuticas ganharam aceitação mundial, pois são capazes de direcionar seletivamente as células. No entanto, essas estratégias também 
demonstraram algumas limitações, como a ausência de resposta ou recaída em alguns pacientes, enquanto outros respondem muito bem ${ }^{14}$. Um dos principais contribuintes para o insucesso das moléculas é muitas vezes uma compreensão incompleta ou insatisfatória dos perfis farmacocinético e da farmacodinâmica, o que leva a uma eficácia limitada ou diminuída ${ }^{15}$.

Ajustar as propriedades farmacocinéticas desses agentes em combinação com os esforços para otimizar sua farmacodinâmica pode levar a moléculas com melhores perfis de segurança e eficácia. Além disso, aperfeiçoar essas propriedades pode facilitar a redução da dose e/ou frequência da dose, melhorando assim a conveniência do paciente, aumentando a adesão e produzindo melhores resultados terapêuticos com sucesso clínico ${ }^{15}$.

\section{Eficácia/vantagens}

Os MAbs são proteínas, sendo degradadas em aminoácidos endógenos, e, portanto, apresentam alta segurança e baixo risco de interação medicamentosa ${ }^{16}$.

Por serem altamente específicos para CGRP ou seu receptor, os CGRP MAbs têm interação mínima com o sistema imunológico e nenhum efeito imunomodulador. Os CGRP MAbs são projetados para ter sequências que se assemelham muito (MAbs humanizados) ou são idênticos (MAbs humanos) a sequências de imunoglobulina humana. Por esse motivo, o risco de imunogenicidade é considerado baixo ${ }^{16}$. 
Devido a esses fatores, foi identificado que os anticorpos monoclonais se apresentam como uma grande alternativa para o tratamento preventivo da enxaqueca, tendo em vista que, apesar de serem efetivos contra a enxaqueca aguda, os antagonistas dos receptores de CGRP apresentaram grande risco (sobretudo hepatotoxicidade) em estudos randomizados. Dessa forma, vários ensaios clínicos de fase 2 mostraram que anticorpos monoclonais de CGRP (MAbs) beneficiam indivíduos que sofrem de enxaqueca em tratamento preventivo sem preocupações com hepatotoxicidade ${ }^{16,17}$. Nos estudos publicados anteriormente, evidenciaram-se dados demonstrando que os MAbs CGRP levam a melhoria na diminuição dos dias de enxaqueca mensais a partir da linha de base de 1-4 semanas e 9-12 semanas, ou seja, entre os vários MAbs observa-se que alguns já começam a agir uma semana após o início do tratamento ${ }^{17,18}$. Quando esses medicamentos estão no corpo humano, há a possibilidade de que anticorpos anti-MAbs possam ser produzidos e que anticorpos neutralizantes possam interferir na eficácia dos medicamentos, tendo em vista o caráter proteico desse tipo de medicamento. No entanto, a presença de anticorpos neutralizantes, com base em estudos clínicos randomizados tem se mostrado infrequente (de 0 a $3,1 \%)^{16}$.

Notavelmente, uma proporção de pacientes com episódios de enxaqueca tratados com anticorpos monoclonais de CGRP teve uma resposta completa, isto é, sem episódios de enxaqueca. Além disso, esses 
medicamentos mostraram-se eficientes também na redução da carga de sintomas não relacionados à dor de cabeça da enxaqueca, incluindo sintomas como náuseas ou vômitos, fotofobia e fonofobia, os quais são sintomas clássicos presentes em crises de recuperação (post-drome) que sucedem os ataques de cefaleia ${ }^{16}$. Esse é um fator importante, visto que alguns pacientes não precisarão mais de um período de descanso para se recuperarem completamente. Embora estudos mostrem que os MAbs CGRP são eficazes e bem tolerados para o tratamento preventivo da enxaqueca, ainda não se pode oferecer as informações sobre a melhor dose ou regime de MAbs CGRP para o tratamento da enxaqueca.

\section{Riscos/Desvantagens}

Uma vez que não é conhecido o efeito desses anticorpos monoclonais durante a gravidez para um feto e, da mesma forma, não se tem evidências concretas dessas moléculas no leite materno, é necessário ter uma atenção especial para esses casos, e aconselhar a mulher em idade fértil, em uso desses fármacos, sobre os métodos de controle da natalidade ${ }^{16}$.

Os pacientes também devem ser rastreados para doença cardiovascular preexistente antes de iniciar 0 tratamento com MAbs CGRP, tendo em vista que o CGRP é um potente vasodilatador em todo o sistema vascular e sua inibição crônica com MAbs poderia ser perigosa por ter potencial para causar hipertensão e facilitar hipoperfusão 
coronária ou cerebral ${ }^{16}$. Em vista disso, em alguns ensaios clínicos foram evidenciados como efeitos adversos mais graves os Ataques Isquêmicos Transitórios. Outro efeito adverso relatado durante os estudos clínicos randomizados foi a ocorrência de reações no local da injeção, que incluíam dor, enrijecimento e eritema com o uso de formulações subcutâneas. Foram relatados, também, em uma pequena minoria dos pacientes casos de infecção do trato respiratório superior, influenza, náusea, sinusite, nasofaringite, artralgia, prurido, dor nas costas, espasmo muscular, dor abdominal, infecção do trato urinário e tontura. No entanto, tais efeitos não apresentaram uma incidência maior quando comparadas com os grupos placebos dos estudos ${ }^{17}$.

Anticorpos monoclonais mais antigos no mercado, como aqueles empregados no tratamento de câncer e doenças relacionadas ao sistema imune, tem valor reconhecidamente elevado e apresentam relação custo-efetividade contraditória em alguns estudos ${ }^{19}$. Essa limitação parece continuar presente com os MABs CGRP. Sussman et al realizaram estudo comparativo do custo-efetividade do tratamento preventivo com Erenumab frente a onabotulinumtoxinA, toxina capaz de bloquear contração muscular também empregada em casos de migrânea refratária. Apesar do custo direto estimado de Erenumab (\$575,00/mês) ser superior ao de onabotulinumtoxinA (\$310,52/mês), o estudo afirma que Erenumab possui custoefetividade válido em pacientes com enxaqueca crônica, que apresentam mais dias com enxaqueca por mês, mas 
representam perda financeira para aqueles com enxaqueca episódica ${ }^{20}$. Avaliando especificamente os custos causados por efeitos adversos, os MAbs CGRP apresentam melhor resultado que onabotulinumtoxinA, sendo o Fremanezumab superior em custo-efetividade, seguido pelo Erenumab ${ }^{21}$.

\section{CONCLUSÃO}

Existem, atualmente, quatro anticorpos monoclonais anti-CGRP disponíveis no mercado, são eles: Erenumab, Galcanezumab, Fremanezumab e o Eptinezumab. A comercialização desses medicamentos indica resultados promissores quanto à eficácia no tratamento e na prevenção de episódios de enxaqueca para os indivíduos que sofrem desse mal, inclusive, com minimização de efeitos adversos. Contudo, há ainda um entrave quanto ao custo desses fármacos, uma vez que, devido seu desenvolvimento recente e suas vantagens em relação aos demais medicamentos disponíveis para o tratamento da enxaqueca, a manutenção de um tratamento com MAbs anti-CGRP demanda despesas elevadas.

\section{AGRADECIMETOS}

À Prof.a Lislane Trajano Romano e à Joelson Henrique de Oliveira Campos pelo suporte na tradução do resumo do presente artigo. 


\section{REFERÊNCIAS}

1.Charles A. The pathophysiology of migraine: implications for clinical management. Lancet Neurol 2018;17:174-82. http://dx.doi.org/10.1016/S1474-4422(17)30435-0

2. De Vries T, Villalón CM, Maassen Van Den Brink A. Pharmacological treatment of migraine: CGRP and 5-HT beyond the triptans. Pharmacol Ther 2020;107528.

https://doi.org/10.1016/j.pharmthera.2020.107528

3.Bohm PE, Stancampiano FF, Rozen TD. Migraine Headache: Updates and Future Developments. Mayo Clin Proc 2018;93:1648-53. https://doi.org/10.1016/j.mayocp.2018.09.006

4. Headache Classification Committee of the International Headache Society (IHS). The International Classification of Headache Disorders, 3rd edition (beta version). Cephalalgia 2013;33:629-808. https://doi.org/10.1177/033310241348565

5.Speciali JG, Kowacs F, Jurno ME, Silvestre Bruscky I, Freitas De Carvalho JJ, Goreth F, et al. Protocolo Nacional Para Diagnóstico E Manejo Das Cefaleias Nas Unidades De Urgência Do Brasil. Acad Bras Neurol 2018;11. https://sbcefaleia.com.br/images/protocolo cefaleia urgencia.pdf

6. Negro A, Koverech A, Martelletti P. Serotonin receptor agonists in the acute treatment of migraine: A review on their therapeutic potential. J Pain Res 2018;11:515-26. https://doi.org/10.2147/JPR.S132833

7.Qubty W, Patniyot I. Migraine Pathophysiology. Pediatr Neurol 2020;107:1-6. https://doi.org/10.1016/j.pediatrneurol.2019.12.014 8. Bordini CA, Roesler C, Carvalho DS, Macedo DDP, Piovesan E, Melhado EM, et al. Recommendations for the treatment of migraine attacks - a Brazilian consensus. Arq Neuropsiquiatr 2016;74:262-71. https://doi.org/10.1590/0004-282X20150219

9.Mayans L, Walling A. Acute Migraine Headache: Treatment Strategies. Am Fam Physician 2018;97:24351.https://www.aafp.org/afp/2018/0215/p243.html

10.Ong JJY, de Felice M. Migraine Treatment: Current Acute Medications and Their Potential Mechanisms of Action. Neurotherapeutics 2018;15:274-90. https://doi.org/10.1007/s13311017-0592-1

11.Edvinsson L. Role of cgrp in migraine. Handb Exp Pharmacol 2019;255:121-30. https://doi.org/10.1007/164_2018_201

12.Akhtar A. The Role of Anti-calcitonin Gene-related Peptide in Migraine and its Implication in Developing Countries: A Reasonable Option to Consider Despite Higher Cost. Cureus 2019;11:6-11. https://doi.org/10.7759/cureus.4796

13.Kumar R, Parray HA, Shrivastava T, Sinha S, Luthra K. Phage display antibody libraries: A robust approach for generation of recombinant human monoclonal antibodies. Int J Biol Macromol 2019;135:907-18. https://doi.org/10.1016/j.ijbiomac.2019.06.006 14.Bordron A, Bagacean C, Tempescul A, Berthou C, Bettacchioli E, Hillion S, et al. Complement System: a Neglected Pathway in Immunotherapy. Clin Rev Allergy Immunol 2020;58:155-71. 
https://doi.org/10.1007/s12016-019-08741-0

15.Datta-Mannan A. Mechanisms influencing the pharmacokinetics and disposition of monoclonal antibodies and peptides. Drug Metab Dispos 2019;47:1100-10. https://doi.org/10.1124/dmd.119.086488

16. Tiseo C, Ornello R, Pistoia F, Sacco S. How to integrate monoclonal antibodies targeting the calcitonin gene-related peptide or its receptor in daily clinical practice. J Headache Pain 2019;20:49.https://doi.org/10.1186/s10194-019-1000-5

17. Hong $\mathrm{P}, \mathrm{Wu} \mathrm{X}$, Liu $\mathrm{Y}$. Calcitonin gene-related peptide monoclonal antibody for preventive treatment of episodic migraine: A meta analysis. Clin Neurol Neurosurg 2017;154:74-8. http://dx.doi.org/10.1016/j.clineuro.2017.01.009

18. Martin V, Samaan KH, Aurora S, Pearlman EM, Zhou C, Li X, et al. Efficacy and Safety of Galcanezumab for the Preventive Treatment of Migraine: A Narrative Review. Adv Ther 2020;37:2034-49. https://doi.org/10.1007/s12325-020-01319-9

19.Park T, Griggs SK, Suh DC. Cost Effectiveness of Monoclonal Antibody Therapy for Rare Diseases: A Systematic Review. BioDrugs 2015;29:259-74. https://doi.org/10.1007/s40259-015-0135-4.

20.Sussman M, Benner J, Neumann P, Menzin J. Cost-effectiveness analysis of erenumab for the preventive treatment of episodic and chronic migraine: Results from the US societal and payer perspectives. Cephalalgia 2018;38:1644-57. https://doi.org/10.1177/0333102418796842.

21.Irimia P, Santos-Lasaosa S, García Bujalance L, Ramos Pinazo L, Rubio-Rodríguez D, Rubio-Terrés C. Cost of fremanezumab, erenumab, galcanezumab and onabotulinumtoxinA associated adverse events, for migraine prophylaxis in Spain. Expert Rev Pharmacoecon Outcomes Res 2020:1-13. https://doi.org/10.1080/14737167.2020.1768850 